\title{
Melatonin-Producing Endophytic Bacteria from Grapevine Roots Promote the Abiotic Stress-Induced Production of Endogenous Melatonin in Their Hosts
}

\section{Jian Jiao', Yaner Ma², Sha Chen³, Chonghuai Liu², Yuyang Song1', Yi Qin', Chunlong Yuan ${ }^{1 *}$ and Yanlin Liu ${ }^{1 *}$}

\author{
${ }^{1}$ College of Enology, Northwest A\&F University, Yangling, China, ${ }^{2}$ Zhengzhou Fruit Research Institute, Chinese Academy of \\ Agricultural Sciences, Zhengzhou, China, ${ }^{3}$ Institute of Chinese Materia Medica, China Academy of Chinese Medical \\ Sciences, Beijing, China
}

OPEN ACCESS

Edited by:

Haitao Shi,

Hainan University, China

Reviewed by:

Yuan Huang,

Huazhong Agricultural University,

China

Shan Yuan,

China Agricultural University, China

*Correspondence:

Yanlin Liu

yanlinliu@nwsuaf.edu.cn

Chunlong Yuan

yuanch169@nwsuaf.edu.cn

Specialty section:

This article was submitted to

Plant Metabolism

and Chemodiversity,

a section of the journal

Frontiers in Plant Science

Received: 02 August 2016

Accepted: 31 August 2016

Published: 21 September 2016

Citation:

Jiao J, Ma Y, Chen S, Liu C, Song Y,

Qin Y, Yuan C, and Liu Y (2016)

Melatonin-Producing Endophytic

Bacteria from Grapevine Roots

Promote the Abiotic Stress-Induced

Production of Endogenous Melatonin

in Their Hosts.

Front. Plant Sci. 7:1387.

doi: 10.3389/fpls.2016.01387
Endophytes form symbiotic relationships with plants and constitute an important source of phytohormones and bioactive secondary metabolites for their hosts. To date, most studies of endophytes have focused on the influence of these microorganisms on plant growth and physiology and their role in plant defenses against biotic and abiotic stressors; however, to the best of our knowledge, the ability of endophytes to produce melatonin has not been reported. In the present study, we isolated and identified root-dwelling bacteria from three grapevine varieties and found that, when cultured under laboratory conditions, some of the bacteria strains secreted melatonin and tryptophan-ethyl ester. The endophytic bacterium Bacillus amyloliquefaciens SB9 exhibited the highest level of in vitro melatonin secretion and also produced three intermediates of the melatonin biosynthesis pathway: 5-hydroxytryptophan, serotonin, and $\mathrm{N}$-acetylserotonin. After B. amyloliquefaciens SB-9 colonization, the plantlets exhibited increased plant growth. Additionally, we found that, in grapevine plantlets exposed to salt or drought stress, colonization by B. amyloliquefaciens SB-9 increased the upregulation of melatonin synthesis, as well as that of its intermediates, but reduced the upregulation of grapevine tryptophan decarboxylase genes (VVTDCs) and a serotonin $N$-acetyltransferase gene (VVSNAT) transcription, when compared to the un-inoculated control. Colonization by $B$. amyloliquefaciens SB-9 was also able to counteract the adverse effects of salt- and drought-induced stress by reducing the production of malondialdehyde and reactive oxygen species $\left(\mathrm{H}_{2} \mathrm{O}_{2}\right.$ and $\left.\mathrm{O}_{2}{ }^{-}\right)$in roots. Therefore, our findings demonstrate the occurrence of melatonin biosynthesis in endophytic bacteria and provide evidence for a novel form of communication between beneficial endophytes and host plants via melatonin.

Keywords: melatonin, endophytic bacteria, UPLC-MS/MS, grapevine, abiotic stress

Abbreviations: IAA, indole-3-acetic acid; MDA, malondialdehyde; ROS, reactive oxygen species; TEE, tryptophan-ethyl ester. 


\section{INTRODUCTION}

Melatonin ( $N$-acetyl-5-methoxytryptamine) was first isolated from the bovine pineal gland (Lerner et al., 1958) and is now recognized as ubiquitous among living organisms, including humans, animals, plants, bacteria, fungi, and macroalgae (Tilden et al., 1997; Rodriguez-Naranjo et al., 2012; Tan et al., 2012). In vertebrates, the molecule functions as a biological modulator of mood, sleep, sexual behavior, seasonal reproductive physiology, and circadian rhythms (Reiter, 1993; Hardeland, 2008; Reiter et al., 2010); as a potent antioxidant, with free radical-scavenging activities; and as a stimulator of antioxidant enzyme activities (Reiter et al., 2005). Meanwhile, the occurrence of melatonin in higher plants wasn't documented until almost 50 years later, when it was reported by both Dubbels et al. (1995) and Hattori et al. (1995). Since then, melatonin has been recognized to function as an abiotic antistressor, by protecting plants against ROS that are produced as a result of harmful abiotic stresses (Posmyk et al., 2008, 2009; Arnao and Hernández-Ruiz, 2009a; Nawaz et al., 2016). In addition, melatonin also functions as a plant regulator, with growth-promoting effects similar to those of IAA, which is a plant hormone in the auxin class (Hernández-Ruiz and Arnao, 2008).

Since the discovery of melatonin in higher plants, the factors that influence the endogenous melatonin levels in plants have remained relatively unexplored. Recently, reports have demonstrated that different abiotic stressors are able to elevate the endogenous melatonin levels of plants (Arnao and HernándezRuiz, 2013a,b; Shi et al., 2015; Hernández-Ruiz and Arnao, 2016) and that stress-induced ROS bursts may be the common factor that triggers the accumulation of melatonin (Arnao and Hernández-Ruiz, 2015). Under natural conditions, the internal organs of plants are frequently colonized by a vast number of diverse microbes that are able to interact with their hosts and, thereby, modulate plant growth and development (Sturz et al., 2000). Soil microbes, for example, have been shown to enter and proliferate within plant roots (Hardoim et al., 2008), and in grapevines, naturally occurring endophytes have been isolated from roots, stems, leaves, and various reproductive tissues (e.g., inflorescences, seeds, and fruits; Compant et al., 2011). These symbiotic organisms are important in defending their hosts against phytopathogens (Lindow and Brandl, 2003; West et al., 2010) and may also promote the growth of their host plants via nitrogen fixation (Elbeltagy et al., 2001), phosphorus solubilization (Richardson et al., 2009), and the enhancement of plant hormones levels (Ali et al., 2009). Therefore, endophytes are generally recognized as important and beneficial components of plant micro-ecosystems. In fact, since endophytes often supply their hosts with plant hormones, we speculate that endophytes are capable of producing melatonin and that they provide melatonin to their plant hosts. This conjecture is based on observations that (i) melatonin has been identified in microorganisms, such as aerobic photosynthetic bacteria (Tilden et al., 1997), recombinant E. coli (Byeon and Back, 2016) and some fungi (Manchester et al., 1995; Hardeland and Poeggeler, 2003); (ii) melatonin biosynthesis is likely to be evolutionarily conserved (Tan et al., 2014); (iii) the cellular machinery for melatonin synthesis in eukaryotes may have been inherited from bacteria, as a result of endosymbiosis (Tan et al., 2013); and (iv) bioinformatic analyses has revealed that enzymes involving in melatonin synthesis occur in bacterial genomes (Pavlicek et al., 2010; Falcón et al., 2014). However, to the best of our knowledge, the ability of endophytic bacteria to produce melatonin has not been reported, and the synthetic pathway of melatonin in heterotrophic bacteria remains to be elucidated.

Therefore, in the present study, we used a culture-dependent method to isolate endophytic bacteria from the roots of three grapevine varieties and screened the resulting cultures for their in vitro capacity to produce melatonin. We subsequently used a promising endophytic strain that produced high levels of melatonin to investigate the intermediates of the melatonin biosynthesis pathway, and in addition, we also performed root colonization experiments, in order to evaluate the effect of the strain on the endogenous melatonin production of host plants under abiotic stress. Finally, to examine whether stress-induced changes in melatonin levels were associated with the induction of melatonin synthesis, we performed qRT-PCR analysis of VvSNAT and several $V v T D C$ senes, both of which play a pivotal role in regulating melatonin biosynthesis in plants (Byeon et al., 2013; Zhao et al., 2013).

\section{MATERIALS AND METHODS}

\section{Isolation of Endophytic Bacteria from Grapevine Roots}

We selected three grapevine varieties for our experiments, including the Chinese wild grapevine Vitis amurensis 'Changbai 9, V. vinifera 'Cabernet Sauvignon,' and V. labruscana 'Summer Black', and collected root samples from plants that were cultivated at the National Grape Germplasm Repository $\left(113^{\circ} 70^{\prime} \mathrm{E} ; 34^{\circ} 72^{\prime}\right.$ N), Zhengzhou Fruit Research Institute, Chinese Academy of Agricultural Sciences, Zhengzhou, Henan, China. The root samples were collected from one vine of each variety, when the vines were in flower, and a total of $5 \mathrm{~g}$ roots were collected from five randomly chosen root sections ( $\sim 20 \mathrm{~cm}$ below ground) each plant and pooled in sterile $15-\mathrm{mL}$ tubes. The pooled root samples were then kept in refrigerated boxes and transported to the laboratory within $1 \mathrm{~h}$ of collection for subsequent processing.

The roots were surface-sterilized in $70 \%$ ethanol for $3 \mathrm{~min}$, followed by soaking in sodium hypochlorite $(3 \%$ available chlorine) for $2 \mathrm{~min}$, and were then rinsed three times with sterile water. Next, each sample was ground and homogenized in 1.5$\mathrm{mL}$ of PBS using sterile quartz sand in individual mortars. The resulting homogenate was serially diluted $\left(10^{-3}, 10^{-4}\right.$, and $\left.10^{-5}\right)$ and plated on nutrient agar ( $3 \mathrm{~g} / \mathrm{L}$ beef extract, $10 \mathrm{~g} / \mathrm{L}$ tryptone, $5 \mathrm{~g} / \mathrm{L} \mathrm{NaCl}$, and $20 \mathrm{~g} / \mathrm{L}$ agar, $\mathrm{pH}$ 7.4) with $100 \mathrm{mg} / \mathrm{L}$ actidione to inhibit the growth of fungi, and each dilution was prepared in triplicate. In parallel, we also checked the efficiency of our surface sterilization procedure by plating $100 \mu \mathrm{L}$ of the last washing solution (i.e., sterile water used for third rinse) onto nutrient agar. Then, after incubation at $28^{\circ} \mathrm{C}$ for $2-3$ days, the number of colony-forming units was counted, and four to six 
representative isolates of each morphology were collected and purified by streaking onto fresh nutrient agar plates. Each purified isolate was maintained at $-80^{\circ} \mathrm{C}$ in $1 \mathrm{~mL}$ sterile nutrient broth that contained $20 \%$ glycerol.

\section{Genomic DNA Extraction and Species Assessment}

DNA extraction was performed using the TIANamp bacteria DNA Kit (Tiangen, Beijing, China), according to the manufacturer's instructions, and in order to identify each of the isolates, we amplified the $16 \mathrm{~S}$ rRNA sequence, using the primers $8 \mathrm{~F}$ ( $5^{\prime}$-AGAGTTTGATCCTGGCTCAG-3') and 1063R (5' -ACGGG CGGTGTGTRC-3') (Wang and Qian, 2009), as well as the gyrB sequence, which encodes the B subunit of the type II topoisomerase DNA gyrase, using the degenerate primers UP-1 ( $5^{\prime}$ GAAGTCATCATGACCGTTCTGCAYGCNGGNGGNAARTTY GA- $\left.3^{\prime}\right)$ and UP-2r (5'-AGCAGGATACGGATGTGCGAGCCRTC NACRTCNGCRTCNGTCAT-3') reported by Yamamoto and Harayama (1995). The resulting PCR products were purified and bi-directionally sequenced, using the same primers that were used for PCR amplification. The sequences were then compared with reference sequences in GenBank, using the online Blastn software $^{1}$, and identification was considered valid when the identity of a contiguous sequence was $\geq 99 \%$.

\section{Screening for Melatonin-Producing Endophytic Bacteria}

After determining the identities of the individual isolates to the lowest possible taxonomic level (i.e., species or genus), we randomly selected individual strains to represent each taxon. The selected strains were inoculated into $10 \mathrm{~mL}$ lysogeny broth medium, and incubated for 24-36 h, until they reached an $\mathrm{OD}_{600}$ of $\sim 1.0-1.5$. Once this concentration was achieved, the liquid medium was removed by centrifugation at $8000 \times g$ and $4^{\circ} \mathrm{C}$ for $10 \mathrm{~min}$, and the resulting pellets were washed once with $10 \mathrm{ml}$ sterile $\mathrm{PBS}$ and re-suspended in $10 \mathrm{~mL}$ minimal medium (Voigt et al., 2007). The cultures were then incubated at $28^{\circ} \mathrm{C}$ for $8 \mathrm{~h}$ to allow for the depletion of amino acids, after which the cell concentration of the cultures was determined using a Petroff-Hausser counting chamber and the cultures were standardized to $10^{8}$ cells $/ \mathrm{mL}$. Next, $1 \mathrm{~mL}$ of each of the standardized bacterial cultures was inoculated into individual brown bottles $(250 \mathrm{~mL})$ that contained $100 \mathrm{~mL}$ of nutrient broth with $200 \mathrm{mg} / \mathrm{L}$ tryptophan, and the cultures were incubated in a rotary shaker at $28^{\circ} \mathrm{C}$ with a rotational speed of $150 \mathrm{rpm}$ in the dark. Cell viability was quantified using the plate counting method with appropriate dilutions. After $36 \mathrm{~h}$, the bacterial cultures were centrifuged and the supernatants were diluted 1:1 with methanol, and the resulting mixtures were passed through a $0.22-\mu \mathrm{m}$ filter and used for preliminary screening of melatonin and TEE production.

To investigate the potential conversion of L-tryptophan to melatonin in the bacterial strain that produced the highest

\footnotetext{
${ }^{1}$ http://www.ncbi.nlm.nih.gov/BLAST
}

concentration of melatonin, we measured the concentrations of several intermediate molecules of melatonin biosynthesis in its culture medium. The strain was cultivated using the procedure described above. In addition, every $6 \mathrm{~h}$, we sampled the bacterial cultures, centrifuged the samples at $8000 \times g$ for $10 \mathrm{~min}$, and diluted the supernatant 1:1 with methanol. Then, after being passed through a $0.22-\mu \mathrm{m}$ filter, the resulting mixtures were analyzed for tryptamine, 5-hydroxytryptophan, serotonin, $\mathrm{N}$-acetylserotonin, and melatonin contents using UPLC-MS/MS.

\section{Colonization Assay}

To determine whether the melatonin-producing endophytic bacteria could influence the endogenous melatonin level in roots, grapevine plantlets were inoculated with a bacterial isolate that produced the highest amount of melatonin. The bacterial inoculum was prepared by inoculating the strain into $100 \mathrm{~mL}$ nutrient broth, incubating the culture for $24-36 \mathrm{~h}$ at $28^{\circ} \mathrm{C}$, centrifuging the culture at $6000 \times g$ for $10 \mathrm{~min}$, and re-suspending and standardizing the inoculum to $10^{7}-10^{8}$ cells $/ \mathrm{mL}$ with $0.9 \%$ sterilized saline solution. The standardized inoculum was then used to inoculate 6-week-old tissue-cultured $V$. labruscana 'Summer Black' plantlets. The roots of the experimental plantlets were immersed in the bacterial inoculum for $1 \mathrm{~min}$, whereas the roots of the control plantlets were treated with $0.9 \%$ sterile saline solution, and afterward, all the plantlets were transferred to $500 \mathrm{~mL}$ culture bottles that contained $150 \mathrm{~g}$ sterile nutrient soil (Pindstrup, Ryomgaard, Denmark) and $40 \mathrm{~mL}$ nutrient-rich water that was prepared with the MS (Murashige and Skoog) basic nutrient medium (Cat\# M519; Phytotechnology ${ }^{2}$ ). The plants were randomly distributed in a greenhouse with a 16-h light/8-h dark cycle at $26^{\circ} \mathrm{C}$ and irrigated with distilled water $(5 \mathrm{~mL})$ every 2 days.

After 20 days of endophyte colonization, we randomly selected 12 plantlets from each of the inoculated and control plantlets, in order to compare their growth, which we assessed by measuring root length, root fresh weight (FW), plant height, and chlorophyll content. The chlorophyll content of fully expanded leaves was analyzed using a chlorophyll ELISA Kit, according to the manufacturer's instructions (Lvyuan, Beijing, China). In addition, the roots were also sampled to determine counts of viable bacteria in the roots of inoculated and control plants, as described in the "Isolation of endophytic bacteria from grapevine roots" section above, and the plate counts of viable bacteria were considered an indicator of bacterial invasion capacity.

Meanwhile, the rest of plantlets were assigned to one of four experimental treatment groups: (i) inoculated plantlets subject to salt stress; (ii) control plantlets subject to salt stress; (iii) inoculated plantlets subject to drought stress; and (iv) control plantlets subject to drought stress. Briefly, $20 \mathrm{~mL} \mathrm{NaCl}$ solutions ( 60 or $120 \mathrm{mM}$ ) were applied to a series of inoculated and control plantlets in order to simulate salt stress, and $20 \mathrm{~mL} \mathrm{10 \%} \mathrm{PEG-}$ 6000 solution was added to another series of inoculated and control plantlets in order to simulate drought stress, with 12 plantlets per treatment. After 4 days, the roots were sampled

\footnotetext{
${ }^{2}$ http://www.phytotechlab.com/
} 
from each plantlet at 9-10:00 AM and ground into powder using liquid nitrogen in individual mortars, and $0.5 \mathrm{~g}$ of each root powder was extracted with $2 \mathrm{~mL}$ of methanol, as described previously (Boccalandro et al., 2011). The resulting extracts were mixed with $2 \mathrm{~mL}$ ultrapure water, centrifuged, passed through a $0.22-\mu \mathrm{m}$ filter, and stored in amber vials for analysis of 5hydroxytryptophan, tryptamine, serotonin, $\mathrm{N}$-acetylserotonin, and melatonin via UPLC-MS/MS.

The $\mathrm{H}_{2} \mathrm{O}_{2}$ levels of the roots were measured according to Patterson et al. (1984), and superoxide production was estimated using the method of Elstner and Heupel (1976). In addition, we assessed the extent of lipid peroxidation in the roots by measuring the MDA content as described by Zhao et al. (2013) with little modification. Briefly, $0.1 \mathrm{~g}$ of each root powder was extracted with $1 \mathrm{~mL}$ of $10 \%(\mathrm{w} / \mathrm{v})$ trichloroacetic acid (TCA), vortexed, and centrifuged at $8000 \times g$ for $10 \mathrm{~min}$. Then, $0.2 \mathrm{ml}$ of each supernatant was mixed with $0.2 \mathrm{ml} 0.5 \%(\mathrm{w} / \mathrm{v})$ thiobarbituric acid (TBA) in $20 \%(\mathrm{w} / \mathrm{v})$ TCA. The mixtures were heated at $100^{\circ} \mathrm{C}$ for $20 \mathrm{~min}$, cooled, and centrifuged at $8000 \times g$ for $10 \mathrm{~min}$. Absorbances were read at 440, 532, and $600 \mathrm{~nm}$, and the MDA concentration ( $\mathrm{nmol} / \mathrm{g} \mathrm{FW}$ ) was calculated according to the formula: $[6.45 \times(\mathrm{A} 532-\mathrm{A} 600)-0.56 \times \mathrm{A} 450] \times \mathrm{V} / \mathrm{W}$, where $\mathrm{V}(\mathrm{mL})$ is the volume of the tissue extract, and $\mathrm{W}(\mathrm{g})$ is the FW.

\section{RNA Extraction and Quantitative Real-Time PCR Analysis}

Total RNA was isolated from the root tissue of stress-induced plantlets, following the CTAB method (Reid et al., 2006), and the resulting RNA was treated with DNase I and converted to cDNA using the PrimeScript RT reagent Kit with gDNA Eraser (Takara, Dalian, China).

Three TDC homologs, which shared conserved functional domains and $>30 \%$ homology with the amino acid sequence of rice tryptophan decarboxylase (GenBank No. XP_015648768), were identified by searching the non-redundant protein and nucleotide sequence data of grapevine (Vitis Vinifera L.) at the National Center for Biotechnology Information (National Institutes of Health, Bethesda, MD, USA), using the tBLASTn, BLASTp, and PSI-BLAST programs (Altschul et al., 1997); and sequence of the grapevine serotonin $N$-acetyltransferase gene (VvSNAT; GenBank No. XM_002266325) was previously predicted by Byeon et al. (2014a). The expression levels of all four genes in the roots of stress-induced plantlets were determined using quantitative real-time PCR (qRT-PCR) analysis with a Roche 480 light cycler System and SYBR Fast qPCR Mix (TaKaRa, Dalian, China). All primers were designed using the NCBI Primer-BLAST service ${ }^{3}$ (Table 1), and the qRT-PCR amplification was performed with the following conditions: $95^{\circ} \mathrm{C}$ for $5 \mathrm{~min}$, followed by 40 cycles of $95^{\circ} \mathrm{C}$ for $5 \mathrm{~s}, 60^{\circ} \mathrm{C}$ for $10 \mathrm{~s}$, and $72^{\circ} \mathrm{C}$ for $15 \mathrm{~s}$; and melting curve analysis was performed using $95^{\circ} \mathrm{C}$ for $5 \mathrm{~s}, 60^{\circ} \mathrm{C}$ for $1 \mathrm{~min}, 97^{\circ} \mathrm{C}$ continuously, and then $40^{\circ} \mathrm{C}$ for $30 \mathrm{~s}$. All the qRT-PCR reactions were performed in triplicate, and the expression levels of the target genes were normalized using the EF1- $\alpha$ gene as an internal reference.

\footnotetext{
${ }^{3}$ http://www.ncbi.nlm.nih.gov/tools/primer-blast/
}

TABLE 1 | Primers used for quantitative real-time PCR.

\begin{tabular}{|c|c|}
\hline Gene & Primers sequences $\left(5^{\prime}-3^{\prime}\right)$ \\
\hline \multirow[t]{2}{*}{$E F-1 \alpha$} & F: GAACTGGGTGCTTGATAGGC \\
\hline & R: AACCAAAATATCCGGAGTAAAAGA \\
\hline \multirow[t]{2}{*}{ VVSNAT } & F: GCCCGTGCTACATCAGATCA \\
\hline & R: TाTGATGCCCTCTGGGTCAG \\
\hline \multirow[t]{2}{*}{ VVTDC1 } & F: CTGCCAGATTCCGCACCTAA \\
\hline & R: TCGCCGCAGGAGAAGTAATC \\
\hline \multirow[t]{2}{*}{ VVTDC2 } & F: CGGAGCTATGGTGTCGTCAA \\
\hline & R: TCCCCCAACAATGGCATGAG \\
\hline \multirow[t]{2}{*}{ VVTDC3 } & F: CCAGAGAAGAAGGGGAAAGCA \\
\hline & R: GGCTCCTGCAGTACGAGTTG \\
\hline
\end{tabular}

\section{UPLC-MS/MS Analysis of Metabolites}

Tryptophan-ethyl ester, tryptamine, 5-hydroxytryptophan, serotonin, $N$-acetylserotonin, and melatonin were purchased from Sigma-Aldrich (St. Louis, MO, USA). Ultrapure water was produced using a Millipore Milli-Q ultrapure water purification unit (Millipore, Bedford, MA, USA). Other solvents, including methanol and formic acid (HPLC grade), were purchased from Merck (Darmstadt, Germany). Stock solutions were prepared by dissolving $10 \mathrm{mg}$ of each standard in $1 \mathrm{~mL}$ methanol under low light conditions; the solutions were then stored at $-80^{\circ} \mathrm{C}$ to prevent degradation. Fresh working solutions were prepared in a methanol:water solution (50:50, v/v).

Quantitative detection was conducted using a UHPLCESI-QQQ-MS (Agilent 1290 and 6460 triple quadrupole mass spectrometry series; Agilent Corporation, Santa Clara, CA, USA). In the solvent system, Milli-Q water that contained $0.1 \%(\mathrm{v} / \mathrm{v})$ formic acid was used as eluent $\mathrm{A}$, and methanol was used as eluent $B$. The analytes were separated using an Agilent ZORBAX Eclipse XDB-C18, Rapid Resolution HT column $(1.8 \mu \mathrm{m}, 3.0 \mathrm{~mm} \times 50 \mathrm{~mm})$ at $42^{\circ} \mathrm{C}$ with linear elution gradient protocols of 0-6 $\mathrm{min}, 5-55 \% \mathrm{~B}, 6-15 \mathrm{~min}$, $55-100 \% \mathrm{~B}$, at $0.2 \mathrm{~mL} / \mathrm{min}$ flow rate. Next, $100 \% \mathrm{~B}$ was kept constant for $2 \mathrm{~min}$ and the column was re-equilibrated for 5 min using the initial solvent composition. The injection volume was $1 \mu \mathrm{L}$. The metabolites were quantitatively detected using the multiple reactions monitoring mode under unit mass-resolution conditions (tryptamine $m / z \quad 161 \rightarrow 144$, 5hydroxytryptophan $m / z \quad 221 \rightarrow 204$, serotonin $m / z \quad 177 \rightarrow 160$, $N$-acetylserotonin $m / z 219 \rightarrow 160$, and melatonin and TEE $m / z$ $233 \rightarrow 174$ ) in positive ion mode. To quantify the analytes, we constructed eight-point calibration curves, using diluted working solutions of external standards. All points on the curves represented the average of three independent determinations. The linearity of the calibration graphs was determined using regression analysis. The limits of detection (LOD) were calculated based on the $\mathrm{S} / \mathrm{N}$ ratio of 3:1. The limits of quantitation (LOQ) were defined as the lowest level that had an $\mathrm{S} / \mathrm{N}$ ratio of 10:1. All the investigated analytes displayed excellent linearity, with correlation coefficients $\left(R^{2}\right)$ ranging from 0.9975 to 0.9988 (Table 2). 
TABLE 2 | UPLC-MS/MS quantitation data for six analytes.

\begin{tabular}{lcccc}
\hline Analyte & $\begin{array}{c}\text { Linearity } \\
\text { range (ng/mL) }\end{array}$ & $\boldsymbol{R}^{\mathbf{2}}$ & $\begin{array}{c}\text { LOD } \\
\mathbf{( n g} / \mathbf{m L})\end{array}$ & $\begin{array}{c}\text { LOQ } \\
\mathbf{( n g} / \mathbf{m L})\end{array}$ \\
\hline Tryptamine & $0.24-24$ & 0.9975 & 0.08 & 0.24 \\
5-Hydroxytryptophan & $0.45-45$ & 0.9984 & 0.15 & 0.45 \\
Serotonin & $0.36-360$ & 0.9988 & 0.12 & 0.36 \\
N-acetylserotonin & $0.18-18$ & 0.9985 & 0.06 & 0.18 \\
Melatonin & $0.12-1.2$ & 0.9984 & 0.04 & 0.12 \\
Tryptophan-ethyl ester & $0.1-10$ & 0.9979 & 0.03 & 0.1 \\
\hline
\end{tabular}

$L O D$, limit of detection; $L O Q$, limit of quantification.

\section{Statistical Analysis}

For each experiment, the results were expressed as the mean \pm standard deviation of data from 3-12 replicates. Statistical evaluation was performed using one-way ANOVA, followed by Tukey's test for the data of preliminary screening of melatonin production and Student's $t$-test for the colonization assay. All the statistical analyses were performed using SPSS (version 19.0; IBM, Armonk, NY, USA), and a $P$-value of $<0.05$ was considered statistically significant.

\section{RESULTS}

\section{Melatonin and TEE Production by Endophytic Bacteria from Grapevine Roots}

No colonies grew on the plates that were inoculated with water from the final washing step of the root sterilization procedure, suggesting that the surface sterilization procedure was effective. For the remaining plates, the highest bacterial count (5.75 $\pm 0.26 \log 10 \mathrm{CFU} / \mathrm{g}$ FW) was detected on those inoculated with the homogenized roots of $V$. labruscana 'Summer Black', followed by those inoculated using $V$. vinifera 'Cabernet Sauvignon' roots (5.23 $\pm 0.18 \log 10 \mathrm{CFU} / \mathrm{g}$ FW) and $V$. amurensis 'Changbai 9' roots (4.89 $\pm 0.22 \log 10 \mathrm{CFU} / \mathrm{g}$ FW). A total of 98 endophytic bacteria strains were isolated from the surface-sterilized roots, and 16S rRNA sequences were amplified from each strain, whereas $g y r B$ sequences were only amplified from 64. Based on comparison with related sequences deposited in the GenBank DNA database, we identified seven different bacterial genera, which included Agrobacterium, Bacillus, Variovorax, Pseudomonas, Streptomyces, Sphingomonas, and Ensifer.

The Streptomyces strains were excluded from the screening of melatonin- and TEE-producing abilities, owing to their abnormal growth and low biomass in nutrient broth. We randomly screened eight endophytic bacterial strains that represented eight species (Table 3). With the exception of B. cereus CS-17 and Sphingomonas sp. VA-16, all the investigated strains secreted tryptophan derivatives into the medium and exhibited species-specific levels of production (Figure 1A). Five of the strains secreted melatonin in vitro, and the highest level $\left(7.75 \mathrm{ng} / 10^{12}\right.$ cells; $0.87 \mathrm{ng} / \mathrm{mL}$; cell count, $11.15 \log 10$ $\mathrm{CFU} / \mathrm{mL}$ ) was produced by $B$. amyloliquefaciens SB-9, followed by $B$. thuringiensis CS-9 $\left(3.33 \mathrm{ng} / 10^{12}\right.$ cells; $0.53 \mathrm{ng} / \mathrm{mL}$; cell count, $11.20 \log 10 \mathrm{CFU} / \mathrm{mL}$ ) and Agrobacterium tumefaciens CS-30 (2.90 ng/10 ${ }^{10}$ cells; $0.22 \mathrm{ng} / \mathrm{mL}$; cell count, $10.88 \log 10$ $\mathrm{CFU} / \mathrm{mL}$ ). TEE has previously been considered as one of the melatonin isomers, and this compound produced the same fragmentation pattern of melatonin using the triple quadrupole mass spectrometry (Figure 1B). We found that six strains, including all the melatonin-producing isolates, were able to produce TEE, with amounts ranging from 0.24 to $19.83 \mathrm{ng} / 10^{12}$ cells.

\section{Characterization of Melatonin Formation in B. amyloliquefaciens SB-9}

The melatonin synthetic pathways of animals and plants have been reported previously (Figure 2A); however, the mechanism of melatonin synthesis in bacteria is currently unknown. We detected 5-hydroxytryptophan, serotonin, $\mathrm{N}$-acetylserotonin, and melatonin after $6 \mathrm{~h}$ of incubation; however, we did not find tryptamine during the incubation. The concentrations of 5-hydroxytryptophan, serotonin, and $\mathrm{N}$-acetylserotonin increased throughout the incubation period, and reached maximum values of $8.82 \pm 1.08$, $3.81 \pm 0.46$, and $8.41 \pm 0.82 \mathrm{ng} / \mathrm{mL}$, respectively, after $30 \mathrm{~h}$ (Figure 2), whereas the concentration of melatonin reached a maximum value of $1.19 \pm 0.12 \mathrm{ng} / \mathrm{mL}$ after $24 \mathrm{~h}$ of incubation and declined slightly thereafter. When the results were expressed as $\mathrm{ng} / 10^{12}$ viable cells, the production capacity for all the investigated metabolites peaked at $6 \mathrm{~h}$ (cell number, $9.87 \log 10 \mathrm{CFU} / \mathrm{mL}$ ) and, thereafter, declined with increasing cell density $(11.76 \log 10 \mathrm{CFU} / \mathrm{mL}$ at $30 \mathrm{~h})$.

\section{Growth Responses of V. labruscana 'Summer Black' Plantlets Treated with B. amyloliquefaciens SB-9}

Based on its high melatonin-producing capacity, we selected B. amyloliquefaciens SB-9 for the inoculation of grapevine plantlets. We observed no symptoms of pathogenicity in the inoculated $V$. labruscana 'Summer Black' plantlets. At 20 days after inoculation, B. amyloliquefaciens SB-9 was successfully re-isolated from inoculated roots, and its identity was verified via sequencing of the $16 \mathrm{~S}$ rRNA region. In addition, the colonies recovered from the inoculated seedling roots exhibited a single morphotype (Figure 3A), and the population density was $5.74 \pm 0.22$ $\log 10 \mathrm{CFU} / \mathrm{g}$ FW (Figure 3B), which indicated a high level of colonization, whereas no colonies were isolated from the control plant roots. Furthermore, we also observed that inoculation with $B$. amyloliquefaciens SB-9 significantly promoted the growth of the grapevine plantlets. In fact, the root length, plant height, FW, and leaf chlorophyll content of the inoculated plantlets were 48.58, 19.46, 41.82, and $41.76 \%$ greater, respectively, than those of the control plantlets (Figures 3C,D), which indicates that the strain can be regarded as a valuable plant growth-promoting rhizobacteria. 
TABLE 3 | Endophytic bacterial strains screened for melatonin production ability.

\begin{tabular}{|c|c|c|c|c|}
\hline \multirow[t]{2}{*}{ Species } & \multirow[t]{2}{*}{ Code } & \multirow[t]{2}{*}{ Origin } & \multicolumn{2}{|c|}{ GenBank accession no. } \\
\hline & & & 16S rRNA gene & gyrB \\
\hline Agrobacterium tumefaciens & CS-30 & Cabernet Sauvignon & KU522188 & KX346711 \\
\hline Bacillus thuringiensis & CS-9 & & KU522196 & KX346714 \\
\hline B. cereus & CS-17 & & KU522189 & KX346713 \\
\hline B. amyloliquefaciens & SB-9 & Summer Black & KX346710 & KX346712 \\
\hline Variovorax sp. & VA10 & Changbai 9 & KX065462 & - \\
\hline Pseudomonas sp. & VA-7 & & KU522198 & KX423685 \\
\hline Ensifer sp. & VA11 & & KX065463 & - \\
\hline Sphingomonas sp. & VA-16 & & KU522199 & - \\
\hline
\end{tabular}

-, no PCR product.

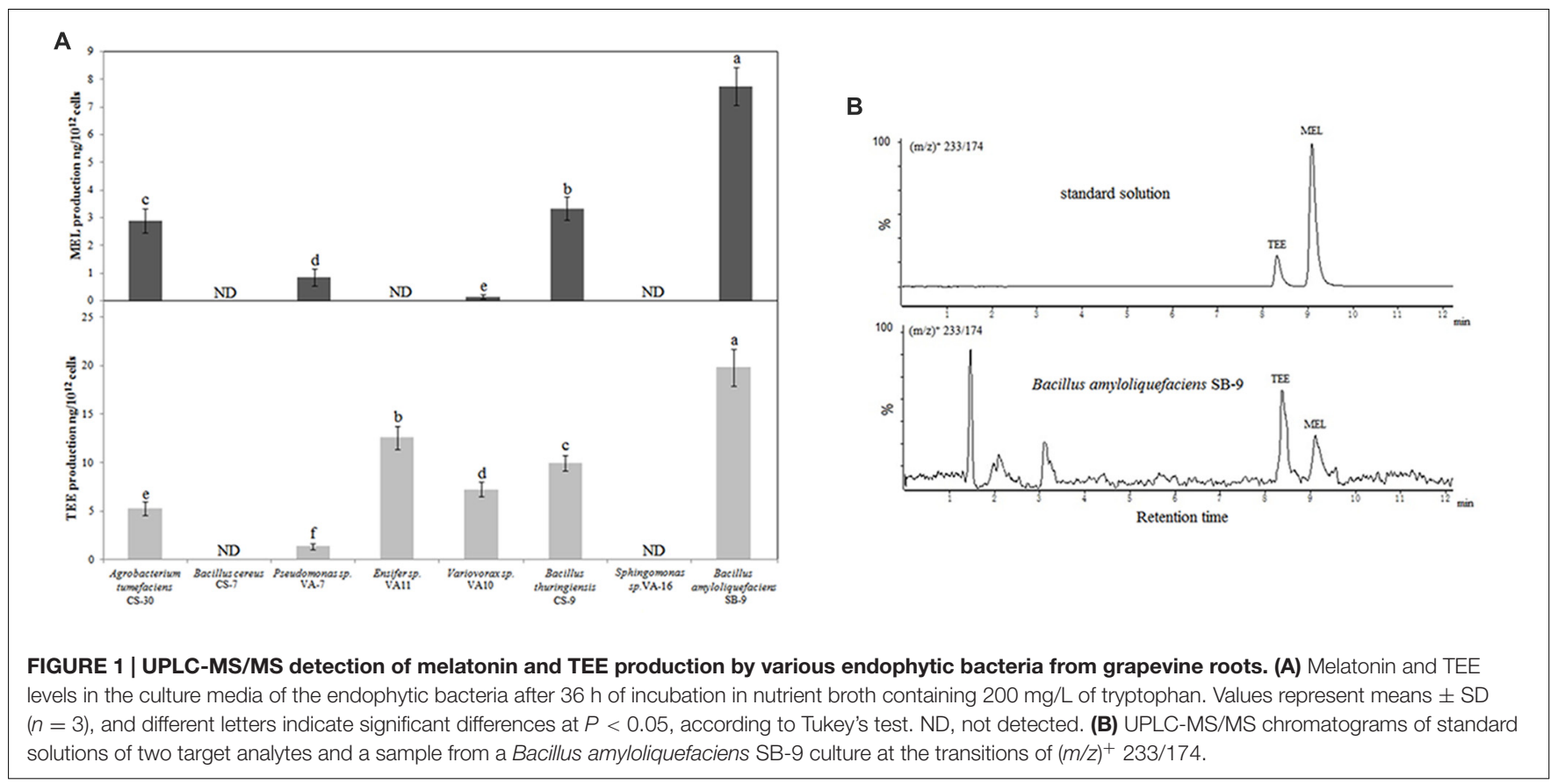

\section{Effect of B. amyloliquefaciens SB-9 on Levels of Endogenous Melatonin and Its Intermediates in Roots under Stress}

When the roots of inoculated and control plantlets were subjected to salt or drought stress, they responded by synthesizing melatonin and its intermediates (tryptamine, 5-hydroxytryptophan, serotonin, and $N$-acetylserotonin), albeit to different extents. We found that melatonin synthesis was similar in the inoculated and control plants under normal growth conditions; however, after exposure to salt or drought stress, the melatonin levels in the roots of inoculated plantlets were 52.61, 37.90 , and $53.07 \%$ higher, respectively, than those in the roots of control plantlets (Figure 4E). Similarly, in the absence of abiotic stresses, 5-hydroxytryptophan levels in inoculated plants and control plants were similar, but after $\mathrm{NaCl}$ or 10\% PEG 6000 treatment, the synthesis of 5-hydroxytryptophan in the roots of inoculated plantlets was significantly higher than that in the roots of control plants (Figure 4B). A similar trend was also observed for $N$-acetylserotonin, and in salt-stress plantlets (120 mM only), its level was significantly upregulated in inoculated plantlets, when compared to control plants (Figure 4C); however, the tryptamine levels in the roots of inoculated plantlets were significantly lower than those in the roots of control plants after exposure to abiotic stresses (Figure 4A), and the serotonin levels in inoculated and control plantlets were statistically similar $(P>0.05$; Figure 4D). Therefore, it is likely that the synthesis of melatonin and its intermediates in the roots of plants exposed to abiotic stress is influenced by B. amyloliquefaciens SB-9 colonization.

\section{Effect of B. amyloliquefaciens SB-9 on Stress-Induced Oxidative Damage}

The MDA level in plant tissue is an indicator of lipid peroxidation status, and it is accompanied by ROS production $\left(\mathrm{H}_{2} \mathrm{O}_{2}\right.$ and $\mathrm{O}_{2}{ }^{-}$). In the absence of abiotic stresses, the MDA level was markedly lower in the roots of inoculated plantlets than 
A

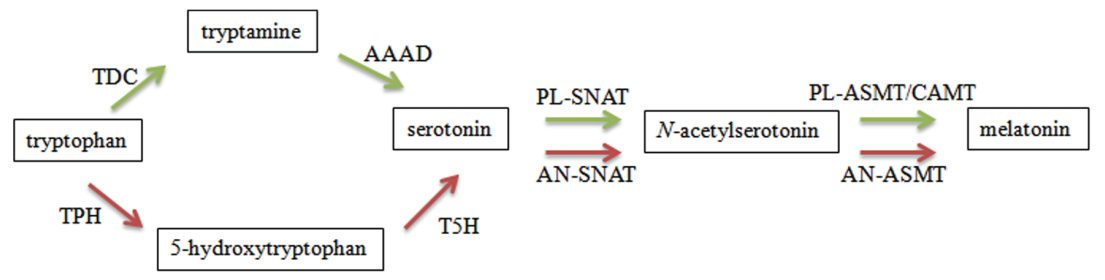

B
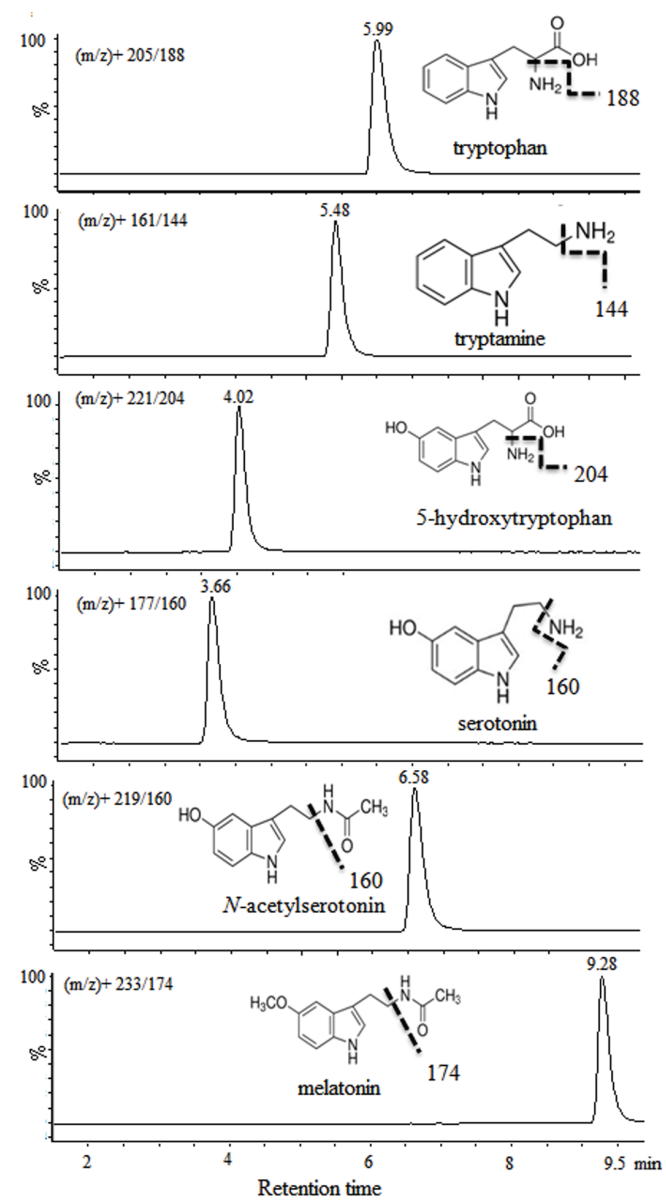

c

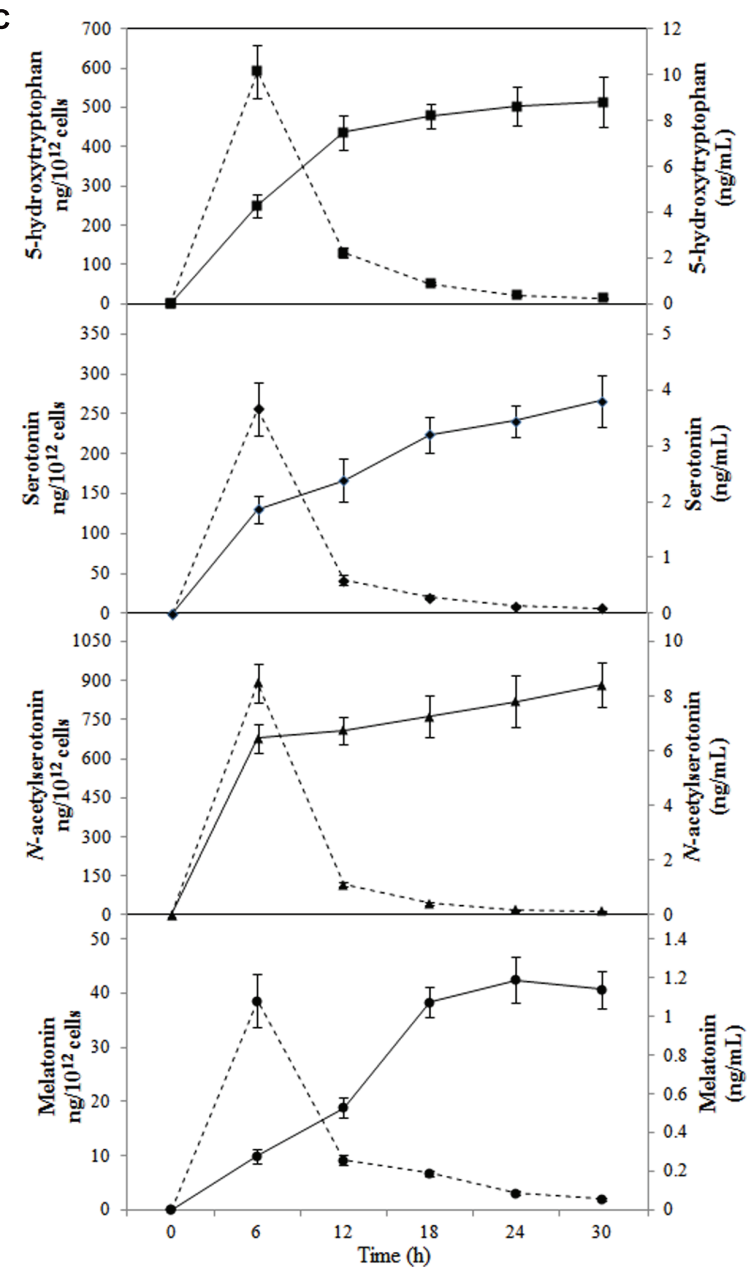

FIGURE 2 | Evolution of metabolite production in melatonin biosynthesis pathway in Bacillus amyloliquefaciens SB-9. (A) Melatonin biosynthesis pathway in animals and plants. Red arrows indicate the animal pathway, and green arrows indicate the plant pathway. TPH, tryptophan hydroxylase; AAAD, aromatic amino acid decarboxylase; TDC, tryptophan decarboxylase; T5H, tryptamine 5-hydroxylase; AN-SNAT, animal serotonin N-acetyltransferase; PL-SNAT, plant serotonin N-acetyltransferase; AN-ASMT, animal N-acetylserotonin O-methyltransferase; PL-ASMT, plant N-acetylserotonin O-methyltransferase; CAMT, caffeic acid O-methyltransferase. (B) Chemical structures and UPLC-MS/MS chromatograms of five standards (40-60 ng/mL). (C) Levels of metabolites involved in the melatonin biosynthesis in a B. amyloliquefaciens SB-9 culture grown in medium containing $200 \mathrm{mg} / \mathrm{L}$ tryptophan. The levels are expressed as ng/mL (solid line) and $\mathrm{ng} / 10^{12}$ cells (dotted line), and the data points represent the means $\pm \operatorname{SD}(n=3)$.

in the roots of un-inoculated plantlets $(3.8 \mathrm{nmol} / \mathrm{g} \mathrm{FW}$ vs. $5.2 \mathrm{nmol} / \mathrm{g} \mathrm{FW}$ ). Additionally, inoculated and un-inoculated plantlets exposed to salt and drought stress had increased MDA levels; however, the MDA levels were significantly lower in the roots of endophyte-associated plantlets than in the roots of un-inoculated plantlets (Figure 5A). We observed similar trends in ROS production between un-inoculated and inoculated plantlets (Figures 5B,C). Our findings indicate that colonization with Bacillus amyloliquefaciens SB-9 counteracted the adverse effects of abiotic stress by reducing the production of MDA and ROS.

\section{Relative Expression of Melatonin Synthesis Genes}

The $V v T D C 1, V v T D C 2$, and $V v T D C 3$ genes are located on grapevine chromosomes 7, 10, and 4, respectively, and their 

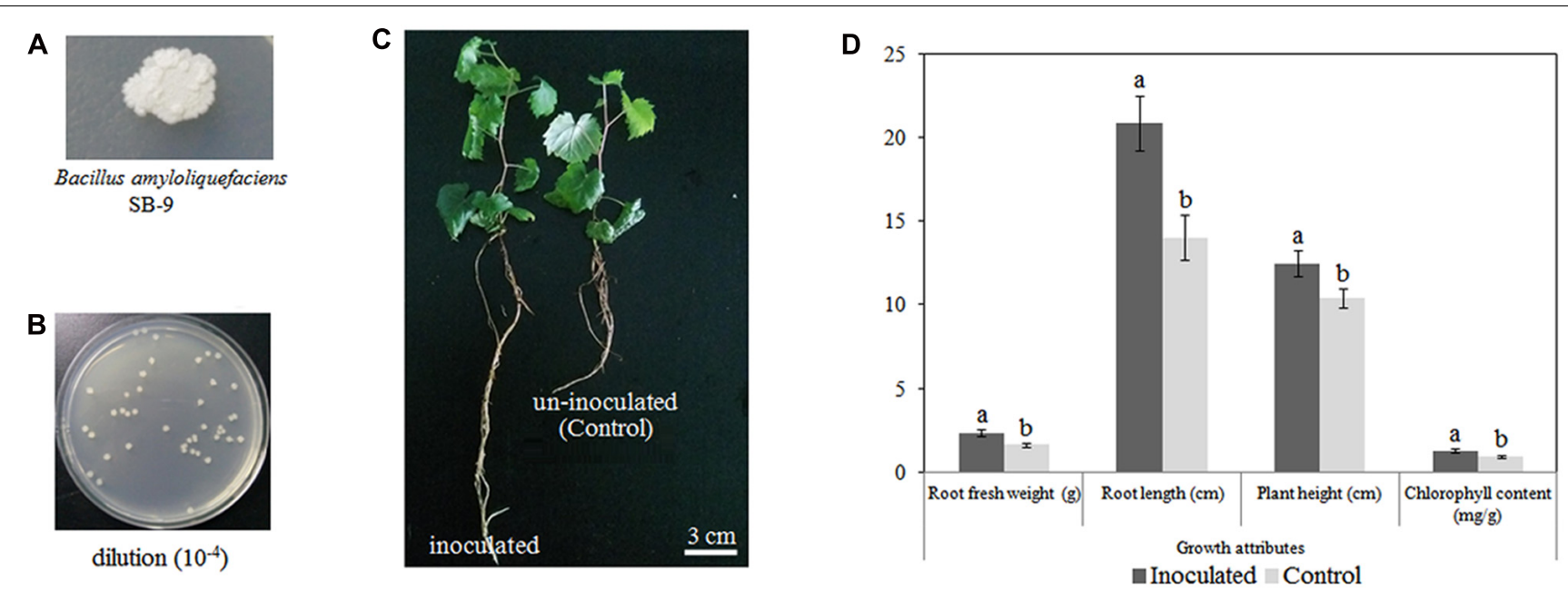

FIGURE 3 | Colonization of Vitis labruscana 'Summer Black' plantlets by Bacillus amyloliquefaciens SB-9. (A) Colony morphotype of B. amyloliquefaciens SB-9. (B) Colony count of bacteria that were re-isolated from inoculated plantlets. (C) Morphological differences between inoculated and control plantlets.

(D) Effects of $B$. amyloliquefaciens SB-9 inoculation on the growth attributes of grapevine plantlets. The values represent means \pm SD ( $n=12$ ). Different letters indicate significant differences $(P<0.05)$ between inoculated and un-inoculated (control) plantlets, according to Student's $t$-test.

predicted amino acid sequences possessed 48.50, 47.87, and $47.49 \%$ homology with rice tryptophan decarboxylase (TDC1). Similar to the pattern observed for endogenous melatonin levels, we observed that the relative expression levels of $V v T D C 1$, $V v T D C 2, V v T D C 3$, and $V v S N A T$ in the roots of control plantlets were significantly upregulated by both salt and drought stress (Figure 6), again suggesting that melatonin synthesis is stressinducible. Interestingly, the transcript levels of the $V v T D C s$ and $V v S N A T$ in the roots of SB-9-inoculated plants were also increased by both salt and drought stress; however, the extent of upregulation for these genes was significantly lower $(P<0.05)$ than that of control plants when they were subject to identical stressors, with the exception of VvTDC1 under $60 \mathrm{mM}$ salt stress.

\section{DISCUSSION}

Melatonin was previously identified in the primitive photosynthetic bacterium Erythrobacter longus (Tilden et al., 1997) and in the gram-negative bacterium Escherichia coli (Hardeland and Poeggeler, 2003); however, few other bacteria are known to produce melatonin. In the present study, we demonstrated that endophytic bacteria, such as A. tumefaciens and B. amyloliquefaciens, are capable of secreting melatonin into extracellular media (Figure 1A). In addition, we also found that the level of melatonin in seedling roots was greater when the roots were colonized by B. amyloliquefaciens SB-9 and subjected to salt or drought stress (Figure 2A). These findings are in accordance with those of Arnao and Hernández-Ruiz (2015), who proposed an association between beneficial endophytes and the enhanced melatonin levels in their host plants. However, we cannot be sure that the enhanced levels of endogenous melatonin were derived from the endophytic bacteria. Alternatively, root cells might utilize intermediate metabolites of melatonin that are produced by endophytic bacteria. In fact, in the present study, B. amyloliquefaciens SB-9 secreted serotonin and $N$-acetylserotonin.

The melatonin biosynthesis pathway of plants was recently described (Byeon et al., 2014b) and was shown to differ markedly from that of vertebrates (Tan et al., 2014). One difference is that plants initially decarboxylate tryptophan to form tryptamine and subsequently hydroxylate tryptamine to form serotonin, whereas vertebrates initially hydroxylate tryptophan to form 5-hydroxytryptophan. In the present study, we failed to detect tryptamine in the B. amyloliquefaciens SB-9 culture; however, the concentration of 5-hydroxytryptophan increased throughout the incubation period (Figure 2C). This suggests that the first step of melatonin biosynthesis in the endophytic bacterium B. amyloliquefaciens SB-9 may be similar to that in vertebrates. However, the entire melatonin biosynthesis pathway remains to be elucidated, and further studies of the genes involved in the melatonin biosynthesis pathway of $B$. amyloliquefaciens SB-9 are required.

Endophytic bacteria play an important role in promoting plant growth; however, their influence might be the result of cumulative effects from the various bioactivities of individual endophytes. Indeed, $\mathrm{N}_{2}$-fixing bacteria are also capable of producing IAA (Pedraza et al., 2004), solubilizing phosphate, and releasing amino acids (Liba et al., 2006). Furthermore, it has also been reported that IAA and gibberellins frequently occur simultaneously in culture broth (Piccoli et al., 2011), which indicates that individual endophytic bacterium may be capable of synthesizing multiple phytohormones. All of the above-mentioned factors are beneficial to plant growth. We found that endophytic bacteria produced an additional growth regulator, melatonin, which was previously reported to stimulate 

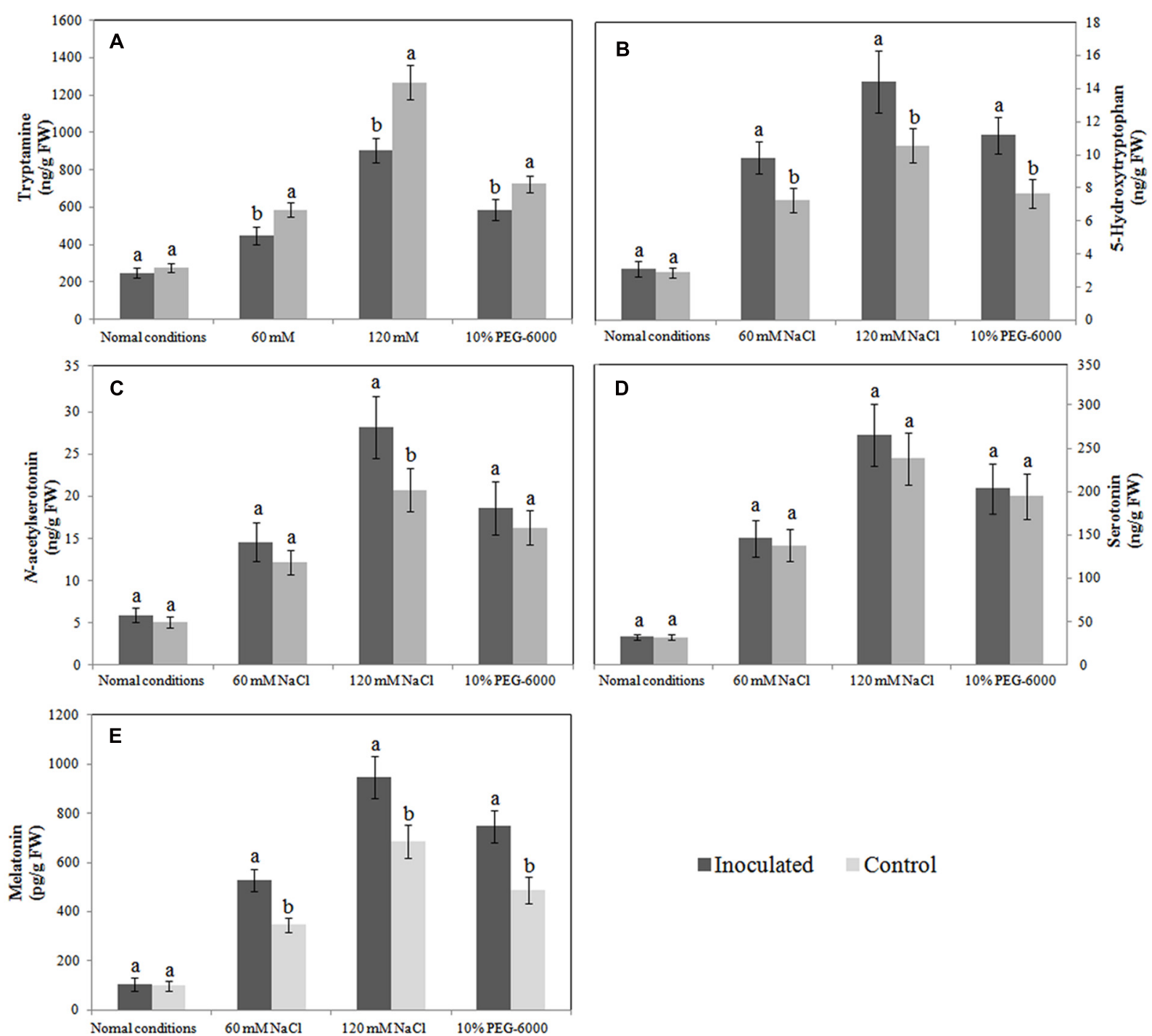

Inoculated Control

FIGURE 4 | Effects of Bacillus amyloliquefaciens SB-9 inoculation on levels of endogenous tryptamine (A), 5-hydroxytryptophan (B), $\mathbf{N}$-acetylserotonin (C), serotonin (D) and melatonin (E) in the roots of salt- and drought-stressed Vitis labruscana 'Summer Black' plantlets. Values represent means $\pm \mathrm{SD}(n=12)$. Different letters indicate significant differences $(P<0.05)$ between inoculated and un-inoculated (control) plantlets, according to Student's $t$-test.

lateral root and shoot growth in several plants, even at low concentrations (Chen et al., 2009; Park and Back, 2012; Bajwa et al., 2014; Wei et al., 2014; Hernández-Ruiz and Arnao, 2016). In the present study, plant height, FW, leaf chlorophyll content, root length, and number of lateral roots (data not shown) were all enhanced by SB-9 colonization. Although we are not sure whether the other B. amyloliquefaciens strains could enhance the endogenous melatonin level in roots, this growthpromoting activity has also been confirmed by other researchers (Idriss et al., 2002; Zhang et al., 2015), Until now, however, we have no direct evidence that the SB-9-derived melatonin enhancement played a role in the growth attributes we measured. This is especially true since the growth promotion, including main/lateral roots development, were likely derived from the combined effects of plant growth-promoting rhizobacteria (PGPR), such as nitrogen fixation, phosphorus solubilization, the production of 1-aminocyclopropane-1-carboxylate (ACC) deaminase or other PGPR-induced physical and chemical (gibberellin, auxin, cytokinin, and unknown metabolites) changes in plants. Further studies, using a mutant that is unable to increase the endogenous melatonin level of roots, are needed to determine the correlation between the enhanced level of melatonin in endophytic bacteria and the promotion of growth in their host plants.

Recent studies have suggested that some plants accumulate melatonin as a defense against a variety of environmental abiotic stressors, such as salt (Mukherjee et al., 2014), chemical agents (Arnao and Hernández-Ruiz, 2009b; Byeon et al., 2015), 

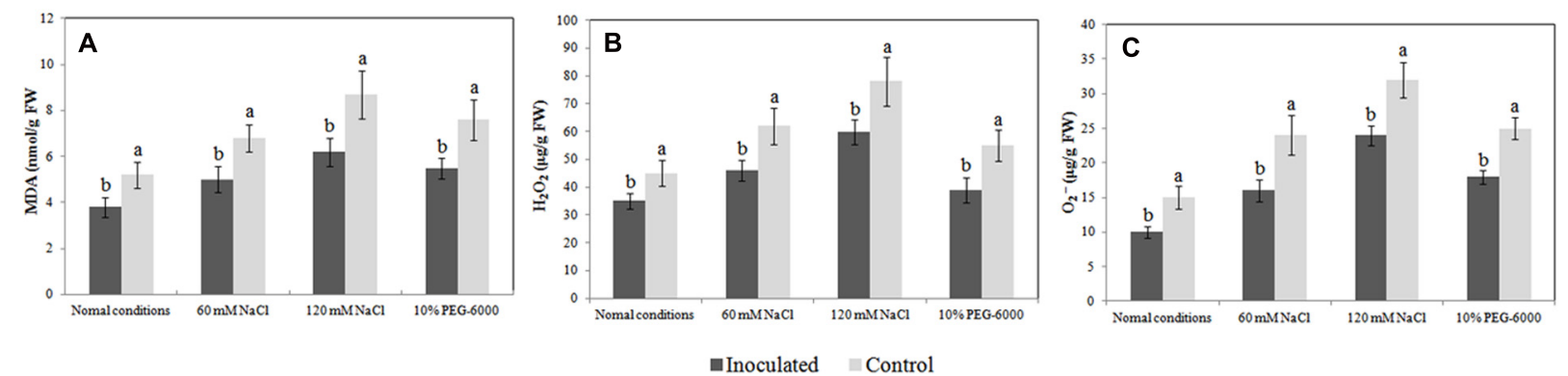

FIGURE 5 | Effects of Bacillus amyloliquefaciens SB-9 inoculation on the levels of malondialdehyde (A), $\mathrm{H}_{2} \mathrm{O}_{2}(\mathrm{~B})$, and $\mathrm{O}_{2}{ }^{-}(\mathrm{C})$ in the roots of salt- and drought-stressed Vitis labruscana 'Summer Black' plantlets. MDA, malondialdehyde. Values represent means \pm SD $(n=12)$. Different letters indicate significant differences $(P<0.05)$ between inoculated and un-inoculated (control) plantlets, according to Student's $t$-test.

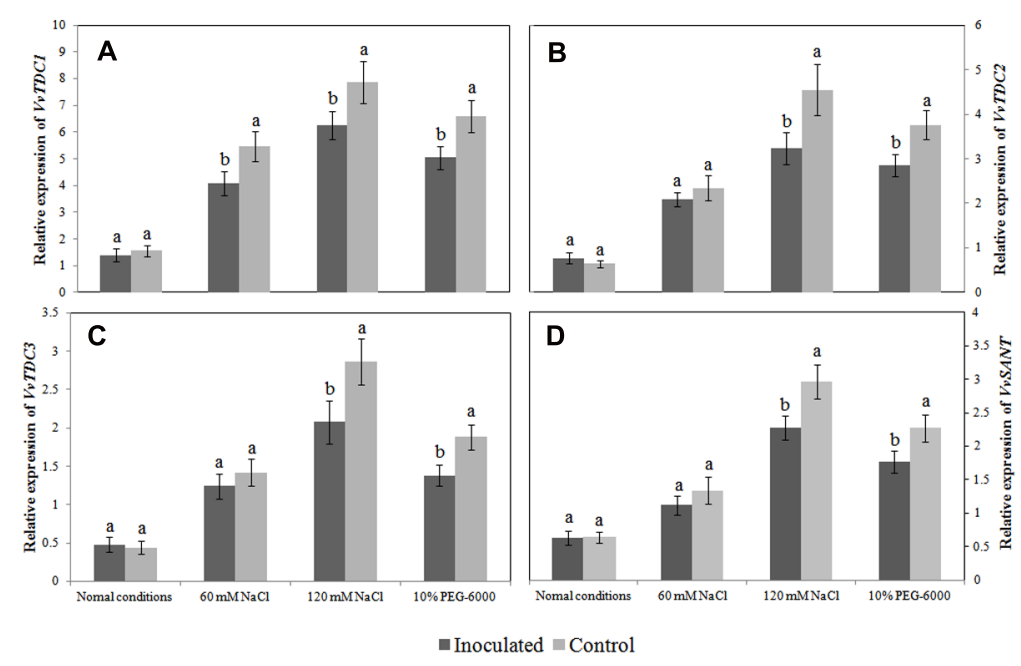

FIGURE 6 | Effects of Bacillus amyloliquefaciens SB-9 inoculation on the relative expression of the VvTDC1 (A), VvTDC2 (B), VvTDC3 (C), and VvSNAT (D) genes in the roots of salt- and drought-stressed Vitis labruscana 'Summer Black' plantlets. The expression levels were normalized according to the expression of grapevine EF1- $\alpha$ mRNA. Values represent means \pm SD $(n=12)$. Different letters indicate significant differences $(P<0.05)$ between inoculated and un-inoculated (control) plantlets, according to Student's t-test.

low temperature (Shi et al., 2015), and drought (Arnao and Hernández-Ruiz, 2013a,b). The results of the present study concur with those of previous reports, and we also found that stress-induced melatonin synthesis was accompanied by the upregulation of several VvTDCs and VvSNAT, as well as the increased production of melatonin intermediates, such as tryptamine, 5-hydroxytryptophan, serotonin, and $N$-acetylserotonin (Figure 4).

Endophytes have mostly been reported to counteract the adverse effects of stress by reducing the production of MDA and ROS in plants (Jungwook et al., 2009; Khan et al., 2012). This behavior is likely derived from the combined effects of endophytes, such as the enhancement of plant antioxidant enzyme (POD, CAT, POD and APX) activities and the production of phenolic compounds or other antioxidant compounds (Torres et al., 2012). We found that, in grapevine plantlets exposed to salt or drought stress, the production of MDA and ROS, as well as the transcript levels of the grapevine $V v T D C s$ and $V v S N A T$ in inoculated roots were relatively lower than those in un-inoculated controls. Therefore, it seems logical that the endogenous levels of melatonin and its intermediates in inoculated roots could be also lower than those in the un-inoculated controls. However, only tryptamine levels exhibited this trend, whereas levels of the other intermediates in the roots of inoculated plants were similar or higher than those in the un-inoculated controls. We speculate that the lower expression of VvTDCs and VvSNAT could be associated with lower oxidative damage in the roots of inoculated plantlets (Figures 5 and 6) because the transcript levels of melatonin synthesis genes were reported to show a positive correlation with ROS levels caused by abiotic stress ( $\mathrm{Li}$ et al., 2014); however, the higher endogenous 5-hydroxytryptophan, $\mathrm{N}$-acetylserotonin and melatonin levels, as well as the statistically similar serotonin level, in the roots of these plantlets was due to SB-9 colonization, which may promote the production of these compounds via supplementary bacterial melatonin biosynthesis, a possible exchange of metabolites between plants and the strain, 
or additional promoting factors produced by the strain. In fact, in the present study, B. amyloliquefaciens SB-9 was able to secrete these compounds in vivo, except tryptamine. In primitive bacteria, melatonin is thought to function as an antioxidant and free radical scavenger that reduces the harmful effects of ROS (Tan et al., 2014). This is the primary role that was reported in both animals and plants (Tan et al., 2002, 2003; Reiter et al., 2005). Therefore, based on these observations, if abiotic stress induces a burst of ROS in the internal tissues of host plants, the living conditions for root-inhabiting microbes presumably become toxic, and as a result, endophytes upregulate their melatonin biosynthesis accordingly, in order to alleviate ROS-induced cell damage.

In summary, the findings of the present study demonstrate that the melatonin-producing ability of endophytic bacteria and the potential application of these bacteria in promoting endogenous melatonin level in plants. However, it remains unclear (i) whether the enhanced levels of endogenous melatonin in roots were derived from production by endophytic bacteria; (ii) whether endophytic fungi produce melatonin; (iii) whether fruit-colonizing endophytes enhance the melatonin levels of fruit tissue, especially in grapevines; (iv) whether any endophytic bacteria, even those with low melatoninproducing abilities, are able to enhance the endogenous melatonin levels in their host plants by providing intermediate metabolites; or (v) which specific internal and external elements influence melatonin production in endophytes and their host plants? Therefore, more comprehensive and detailed investigations are needed to characterize the role

\section{REFERENCES}

Ali, B., Sabri, A., Ljung, K., and Hasnain, S. (2009). Auxin production by plant associated bacteria: impact on endogenous IAA content and growth of Triticum aestivum L. Lett. Appl. Microbiol. 48, 542-547. doi: 10.1111/j.1472765X.2009.02565.X

Altschul, S. F., Madden, T. L., Schäffer, A. A., Zhang, J., Zhang, Z., Miller, W., et al. (1997). Gapped BLAST and PSI-BLAST: a new generation of protein database search programs. Nucleic Acids Res. 25, 3389-3402. doi: 10.1093/nar/25. 17.3389

Arnao, M. B., and Hernández-Ruiz, J. (2009a). Protective effect of melatonin against chlorophyll degradation during the senescence of barley leaves. J. Pineal Res. 46, 58-63. doi: 10.1111/j.1600-079X.2008.00625.x

Arnao, M. B., and Hernández-Ruiz, J. (2009b). Chemical stress by different agents affects the melatonin content of barley roots. J. Pineal Res. 46, 295-299. doi: 10.1111/j.1600-079X.2008.00660.x

Arnao, M. B., and Hernández-Ruiz, J. (2013a). Growth conditions influence the melatonin content of tomato plants. Food Chem. 138, 1212-1214. doi: 10.1016/j.foodchem.2012.10.077

Arnao, M. B., and Hernández-Ruiz, J. (2013b). Growth conditions determine different melatonin levels in Lupinus albus L. J. Pineal Res. 55, 149-155. doi: 10.1111/jpi.12055

Arnao, M. B., and Hernández-Ruiz, J. (2015). Functions of melatonin in plants: a review. J. Pineal Res. 59, 133-150. doi: 10.1111/jpi.12253

Bajwa, V. S., Shukla, M. R., Sherif, S. M., Murch, S. J., and Saxena, P. K. (2014). Role of melatonin in alleviating cold stress in Arabidopsis thaliana. J. Pineal Res. 56, 238-245. doi: 10.1111/jpi.12115

Boccalandro, H. E., González, C. V., Wunderlin, D. A., and Silva, M. F. (2011). Melatonin levels, determined by LC-ESI-MS/MS, fluctuate during the day/night cycle in Vitis vinifera cv Malbec: evidence of its antioxidant role in fruits. J. Pineal Res. 51, 226-232. doi: 10.1111/j.1600-079X.2011.00884.x of melatonin biosynthesis in naturally occurring symbiotic relationships.

\section{AUTHOR CONTRIBUTIONS}

YL, CY, JJ, YS, and YQ conceived the study; JJ and YM performed the experiments, analyzed the data, and wrote the manuscript; SC analyzed the UPLC-MS/MS data; CL provided suggestions and revised the manuscript. All authors approved the final manuscript and agreed to be accountable for all aspects of the work, i.e., ensuring that questions related to the accuracy or integrity of any part of the work are appropriately investigated and resolved.

\section{FUNDING}

This work was supported by a project grant from the National Natural Science Fund Program of China (No. 31571812; http: //www.nsfc.gov.cn).

\section{ACKNOWLEDGMENTS}

We thank Zhang Hongming for valuable advice and are grateful to Dr. Dun-Xian Tan (Department of Cellular and Structural Biology, The University of Texas, Health Science Center at San Antonio) for critical comments.

Byeon, Y., and Back, K. (2016). Melatonin production in Escherichia coli by dual expression of serotonin $\mathrm{N}$-acetyltransferase and caffeic acid O-methyltransferase. Appl. Microbiol. Biotechnol. 100, 6683-6691. doi: 10.1007/s00253-016-7458-Z

Byeon, Y., Lee, H. Y., Choi, D. W., and Back, K. (2014a). Chloroplastencoded serotonin $\mathrm{N}$-acetyltransferase in the red alga Pyropia yezoensis: gene transition to the nucleus from chloroplasts. J. Exp. Bot. 66, 709-717. doi: 10.1093/jxb/eru357

Byeon, Y., Lee, H. Y., Hwang, O. J., Lee, H. J., Lee, K., and Back, K. (2015). Coordinated regulation of melatonin synthesis and degradation genes in rice leaves in response to cadmium treatment. J. Pineal Res. 58, 470-478. doi: 10.1111/jpi.12232

Byeon, Y., Lee, H. Y., Lee, K., Park, S., and Back, K. (2014b). Cellular localization and kinetics of the rice melatonin biosynthetic enzymes SNAT and ASMT. J. Pineal Res. 56, 107-114. doi: 10.1111/jpi.12103

Byeon, Y., Lee, K., Park, Y. I., Park, S., and Back, K. (2013). Molecular cloning and functional analysis of serotonin $\mathrm{N}$-acetyltransferase from the cyanobacterium Synechocystis sp. PCC 6803. J. Pineal Res. 55, 371-376. doi: 10.1111/jpi. 12080

Chen, Q., Qi, W. B., Reiter, R. J., Wei, W., and Wang, B. M. (2009). Exogenously applied melatonin stimulates root growth and raises endogenous indoleacetic acid in roots of etiolated seedlings of Brassica juncea. J. Plant Physiol. 166, 324-328. doi: 10.1016/j.jplph.2008.06.002

Compant, S., Mitter, B., Colli-Mull, J. G., Gangl, H., and Sessitsch, A. (2011). Endophytes of grapevine flowers, berries, and seeds: identification of cultivable bacteria, comparison with other plant parts, and visualization of niches of colonization. Microb. Ecol. 62, 188-197. doi: 10.1007/s00248-011-9883-y

Dubbels, R., Reiter, R. J., Klenke, E., Goebel, A., Schnakenberg, E., Ehlers, C., et al. (1995). Melatonin in edible plants identified by radioimmunoassay and by high performance liquid chromatography-mass spectrometry. J. Pineal Res. 18, 28-31. doi: 10.1111/j.1600-079X.1995.tb00136.x 
Elbeltagy, A., Nishioka, K., Sato, T., Suzuki, H., Ye, B., Hamada, T., et al. (2001). Endophytic colonization and in planta nitrogen fixation by a Herbaspirillum sp. isolated from wild rice species. Appl. Environ. Microb. 67, 5285-5293. doi: 10.1128/AEM.67.11.5285-5293.2001

Elstner, E. F., and Heupel, A. (1976). Inhibition of nitrite formation from hydroxylammoniumchloride: a simple assay for superoxide dismutase. Anal. Biochem. 70, 616-620. doi: 10.1016/0003-2697(76)90488-7

Falcón, J., Coon, S. L., Besseau, L., Cazaméa-Catalan, D., Fuentès, M., Magnanou, E., et al. (2014). Drastic neofunctionalization associated with evolution of the timezyme AANAT 500 Mya. Proc. Natl. Acad. Sci. U.S.A. 111, 314-319. doi: 10.1073/pnas.1312634110

Hardeland, R. (2008). Melatonin, hormone of darkness and more: occurrence, control mechanisms, actions and bioactive metabolites. Cell. Mol. Life Sci. 65, 2001-2018. doi: 10.1007/s00018-008-8001-x

Hardeland, R., and Poeggeler, B. (2003). Non-vertebrate melatonin. J. Pineal Res. 34, 233-241. doi: 10.1034/j.1600-079X.2003.00040.x

Hardoim, P. R., van Overbeek, L. S., and van Elsas, J. D. (2008). Properties of bacterial endophytes and their proposed role in plant growth. Trends Microbiol. 16, 463-471. doi: 10.1016/j.tim.2008.07.008

Hattori, A., Migitaka, H., Iigo, M., Itoh, M., Yamamoto, K., Ohtani-Kaneko, R., et al. (1995). Identification of melatonin in plants and its effects on plasma melatonin levels and binding to melatonin receptors in vertebrates. Biochem. Mol. Biol. Int. 35, 627-634.

Hernández-Ruiz, J., and Arnao, M. B. (2008). Melatonin stimulates the expansion of etiolated lupin cotyledons. Plant Growth Regul. 55, 29-34. doi: 10.1007/s10725-008-9254-y

Hernández-Ruiz, J., and Arnao, M. B. (2016). Phytomelatonin, an interesting tool for agricultural crops. Focus Sci. 2. doi: 10.20286/focsci-020227

Idriss, E. E., Makarewicz, O., Farouk, A., Rosner, K., Greiner, R., Bochow, H., et al. (2002). Extracellular phytase activity of Bacillus amyloliquefaciens FZB45 contributes to its plant-growth-promoting effect. Microbiology 148, 2097-2109. doi: 10.1099/00221287-148-7-2097

Jungwook, Y., Kloepper, J. W., and Choong-Min, R. (2009). Rhizosphere bacteria help plants tolerate abiotic stress. Trends Plant Sci. 14, 1-4. doi: 10.1016/j.tplants.2008.10.004

Khan, A. L., Hamayun, M., Kang, S. M., Kim, Y. H., Jung, H. Y., Lee, J. H., et al. (2012). Endophytic fungal association via gibberellins and indole acetic acid can improve plant growth under abiotic stress: an example of Paecilomyces formosus LHL10. BMC Microbiol. 12:3. doi: 10.1186/1471-2180-12-3

Lerner, A. B., Case, J. D., Takahashi, Y., Lee, T. H., and Mori, N. (1958). Isolation of melatonin, pineal factor that lightens melanocytes. J. Am. Chem. Soc. 80:2587. doi: $10.1021 /$ ja01543a060

Li, C., Tan, D. X., Liang, D., Chang, C., Jia, D., and Ma, F. (2014). Melatonin mediates the regulation of ABA metabolism, free-radical scavenging, and stomatal behaviour in two Malus species under drought stress. J. Exp. Bot. 66, 669-680. doi: 10.1093/jxb/eru476

Liba, C., Ferrara, F., Manfio, G., Fantinatti-Garboggini, F., Albuquerque, R., Pavan, C., et al. (2006). Nitrogen-fixing chemo-organotrophic bacteria isolated from cyanobacteria-deprived lichens and their ability to solubilize phosphate and to release amino acids and phytohormones. J. Appl. Microbiol. 101, 10761086. doi: 10.1111/j.1365-2672.2006.03010.x

Lindow, S. E., and Brandl, M. T. (2003). Microbiology of the phyllosphere. Appl. Environ. Microb. 69, 1875-1883. doi: 10.1128/AEM.69.4.1875-1883. 2003

Manchester, L. C., Poeggeler, B., Alvares, F. L., Ogden, G. B., and Reiter, R. J. (1995). Melatonin immunoreactivity in the photosynthetic prokaryote Rhodospirillum rubrum: implications for an ancient antioxidant system. Cell Mol. Biol. Res. 41, 391-395.

Mukherjee, S., David, A., Yadav, S., Baluška, F., and Bhatla, S. C. (2014). Salt stressinduced seedling growth inhibition coincides with differential distribution of serotonin and melatonin in sunflower seedling roots and cotyledons. Physiol. Plant. 152, 714-728. doi: 10.1111/ppl.12218

Nawaz, M. A., Huang, Y., Bie, Z., Ahmed, W., Reiter, R. J., Niu, M., et al. (2016). Melatonin: current status and future perspectives in plant science. Front. Plant Sci. 6:1230. doi: 10.3389/fpls.2015.01230

Park, S., and Back, K. (2012). Melatonin promotes seminal root elongation and root growth in transgenic rice after germination. J. Pineal Res. 53, 385-389. doi: 10.1111/j.1600-079X.2012.01008.x
Patterson, B. D., Macrae, E. A., and Ferguson, I. B. (1984). Estimation of hydrogen peroxide in plant extracts using titanium (IV). Anal. Biochem. 139, 487-492. doi: 10.1016/0003-2697(84)90039-3

Pavlicek, J., Sauzet, S., Besseau, L., Coon, S. L., Weller, J. L., Boeuf, G., et al. (2010). Evolution of AANAT: expansion of the gene family in the cephalochordate amphioxus. BMC Evol. Biol. 10:154. doi: 10.1186/1471-2148-10-154

Pedraza, R. O., Ramírez-Mata, A., Xiqui, M. L., and Baca, B. E. (2004). Aromatic amino acid aminotransferase activity and indole-3-acetic acid production by associative nitrogen-fixing bacteria. FEMS Microbiol. Lett. 233, 15-21. doi: 10.1016/j.femsle.2004.01.047

Piccoli, P., Travaglia, C., Cohen, A., Sosa, L., Cornejo, P., Masuelli, R., et al. (2011). An endophytic bacterium isolated from roots of the halophyte Prosopis strombulifera produces ABA, IAA, gibberellins A1 and A3 and jasmonic acid in chemically-defined culture medium. Plant Growth Regul. 64, 207-210. doi: 10.1007/s10725-010-9536-z

Posmyk, M. M., Bałabusta, M., Wieczorek, M., Sliwinska, E., and Janas, K. (2009). Melatonin applied to cucumber (Cucumis sativus L.) seeds improves germination during chilling stress. J. Pineal Res. 46, 214-223. doi: 10.1111/j.1600-079X.2008.00652.x

Posmyk, M. M., Kuran, H., Marciniak, K., and Janas, K. M. (2008). Presowing seed treatment with melatonin protects red cabbage seedlings against toxic copper ion concentrations. J. Pineal Res. 45, 24-31. doi: 10.1111/j.1600079X.2007.00552.x

Reid, K. E., Olsson, N., Schlosser, J., Peng, F., and Lund, S. T. (2006). An optimized grapevine RNA isolation procedure and statistical determination of reference genes for real-time RT-PCR during berry development. BMC Plant Biol. 6:27. doi: 10.1186/1471-2229-6-27

Reiter, R. J. (1993). The melatonin rhythm: both a clock and a calendar. Experientia 49, 654-664. doi: 10.1007/BF01923947

Reiter, R. J., Tan, D. X., and Fuentes-Broto, L. (2010). Melatonin: a multitasking molecule. Prog. Brain Res. 181, 127-151. doi: 10.1016/S0079-6123(08)81008-4

Reiter, R. J., Tan, D. X., and Maldonado, M. D. (2005). Melatonin as an antioxidant: physiology versus pharmacology. J. Pineal Res. 39, 215-216. doi: 10.1111/j.1600079X.2005.00261.x

Richardson, A. E., Barea, J. M., Mcneill, A. M., and Prigent-Combaret, C. (2009). Acquisition of phosphorus and nitrogen in the rhizosphere and plant growth promotion by microorganisms. Plant Soil 321, 305-339. doi: 10.1007/s11104009-9895-2

Rodriguez-Naranjo, M. I., Torija, M. J., Mas, A., Cantos-Villar, E., and GarciaParrilla, M. D. C. (2012). Production of melatonin by Saccharomyces strains under growth and fermentation conditions. J. Pineal Res. 53, 219-224. doi: 10.1111/j.1600-079X.2012.00990.x

Shi, H., Jiang, C., Ye, T., Tan, D. X., Reiter, R. J., Zhang, H., et al. (2015). Comparative physiological, metabolomic, and transcriptomic analyses reveal mechanisms of improved abiotic stress resistance in bermudagrass [Cynodon dactylon (L). Pers.] by exogenous melatonin. J. Exp. Bot. 66, 681-694. doi: $10.1093 /$ jxb/eru373

Sturz, A., Christie, B., and Nowak, J. (2000). Bacterial endophytes: potential role in developing sustainable systems of crop production. Crit. Rev. Plant Sci. 19, 1-30. doi: 10.1080/07352680091139169

Tan, D. X., Hardeland, R., Manchester, L. C., Korkmaz, A., Ma, S., RosalesCorral, S., et al. (2012). Functional roles of melatonin in plants, and perspectives in nutritional and agricultural science. J. Exp. Bot. 63, 577-597. doi: $10.1093 /$ jxb/err256

Tan, D. X., Hardeland, R., Manchester, L. C., Poeggeler, B., Lopez-Burillo, S., Mayo, J. C., et al. (2003). Mechanistic and comparative studies of melatonin and classic antioxidants in terms of their interactions with the ABTS cation radical. J. Pineal Res. 34, 249-259. doi: 10.1034/j.1600-079X.2003.00037.x

Tan, D. X., Manchester, L. C., Liu, X., Rosales-Corral, S. A., Acuna-Castroviejo, D., and Reiter, R. J. (2013). Mitochondria and chloroplasts as the original sites of melatonin synthesis: a hypothesis related to melatonin's primary function and evolution in eukaryotes. J. Pineal Res. 54, 127-138. doi: 10.1111/jpi.12026

Tan, D. X., Reiter, R. J., Manchester, L. C., Yan, M., El-Sawi, M., Sainz, R. M., et al. (2002). Chemical and physical properties and potential mechanisms: melatonin as a broad spectrum antioxidant and free radical scavenger. Curr. Top. Med. Chem. 2, 181-197. doi: 10.2174/1568026023394443

Tan, D. X., Zheng, X., Kong, J., Manchester, L. C., Hardeland, R., Kim, S. J., et al. (2014). Fundamental issues related to the origin of melatonin and melatonin 
isomers during evolution: relation to their biological functions. Int. J. Mol. Sci. 15, 15858-15890. doi: 10.3390/ijms150915858

Tilden, A. R., Becker, M. A., Amma, L. L., Arciniega, J., and McGaw, A. K. (1997). Melatonin production in an aerobic photosynthetic bacterium: an evolutionarily early association with darkness. J. Pineal Res. 22, 102-106. doi: 10.1111/j.1600-079X.1997.tb00310.x

Torres, M. S., White, J. F., Zhang, X., Hinton, D. M., and Bacon, C. W. (2012). Endophyte-mediated adjustments in host morphology and physiology and effects on host fitness traits in grasses. Fungal Ecol. 5, 322-330. doi: 10.1016/j.funeco.2011.05.006

Voigt, B., Hoi, L. T., Jürgen, B., Albrecht, D., Ehrenreich, A., Veith, B., et al. (2007). The glucose and nitrogen starvation response of Bacillus licheniformis. Proteomics 7, 413-423. doi: 10.1002/pmic.200600556

Wang, Y., and Qian, P. Y. (2009). Conservative fragments in bacterial $16 \mathrm{~S}$ rRNA genes and primer design for $16 \mathrm{~S}$ ribosomal DNA amplicons in metagenomic studies. PLOS ONE 4:e7401. doi: 10.1371/journal.pone. 0007401

Wei, W., Li, Q. T., Chu, Y. N., Reiter, R. J., Yu, X. M., Zhu, D. H., et al. (2014). Melatonin enhances plant growth and abiotic stress tolerance in soybean plants. J. Exp. Bot. 66, 695-707. doi: 10.1093/jxb/eru392

West, E. R., Cother, E. J., Steel, C. C., and Ash, G. J. (2010). The characterization and diversity of bacterial endophytes of grapevine. Can. J. Microbiol. 56, 209-216. doi: $10.1139 /$ w10-004
Yamamoto, S., and Harayama, S. (1995). PCR amplification and direct sequencing of gyrB genes with universal primers and their application to the detection and taxonomic analysis of Pseudomonas putida strains. Appl. Environ. Microb. 61, 1104-1109.

Zhang, N., Yang, D., Wang, D., Miao, Y., Shao, J., Zhou, X., et al. (2015). Whole transcriptomic analysis of the plant-beneficial rhizobacterium Bacillus amyloliquefaciens SQR9 during enhanced biofilm formation regulated by maize root exudates. BMC Genomics 16:685. doi: 10.1186/s12864-015-1825-5

Zhao, Y., Tan, D. X., Lei, Q., Chen, H., Wang, L., Li, Q. T., et al. (2013). Melatonin and its potential biological functions in the fruits of sweet cherry. J. Pineal Res. 55, 79-88. doi: 10.1111/jpi.12044

Conflict of Interest Statement: The authors declare that the research was conducted in the absence of any commercial or financial relationships that could be construed as a potential conflict of interest.

Copyright (C) 2016 Jiao, Ma, Chen, Liu, Song, Qin, Yuan and Liu. This is an openaccess article distributed under the terms of the Creative Commons Attribution License (CC BY). The use, distribution or reproduction in other forums is permitted, provided the original author(s) or licensor are credited and that the original publication in this journal is cited, in accordance with accepted academic practice. No use, distribution or reproduction is permitted which does not comply with these terms. 